\title{
Secure Connected Transactions using Face Verification
}

\author{
MR.P.C.Karthik, M.Sai Deepthi, K.Abhiram
}

\begin{abstract}
In this day and age, cash can be required whenever or anyplace, for example, shopping, voyaging or wellbeing crises and so on. That additionally expands the danger of getting robed. Bank is a most secure spot to keep cash. In any case, consider the possibility that somebody will take your card and by one way or another he/she will know your secret key, it will give him/her full access to your cash. According to the present situation the online exchange is secure with one time secret word (OTP). In age of OTP there are numerous variables that can make OTP special each time it is produced. Right now execute client Identification utilizing Face Recognition to confirm the client. If there should be an occurrence of crisis circumstance the login should be possible utilizing OTP and furthermore the individual picture is caught and Mail to the Account Holder. Accordingly our framework is improve in Security contrasting with the current System.

Keywords:OTP.
\end{abstract}

\section{INTRODUCTION}

Presently a days with the system world, the path for cybercrime is gotten simpler for haking reason. On account of this explanation, arrange security has gotten one of the greatest confronting the present IT offices security. We heard a ton about programmers and wafers approaches to take any sensible secret phrase or pin code number character, wrongdoings of ID cards or Mastercards misrepresentation or security breaks in any significant structure and afterward build up any data or different significant information from any association or organization. These issues permit us to know the need of solid facial innovation to verify significant information and certifications. This innovation depends on a system called "face acknowledgment" utilizing biometric. Biometric is a type of bio-informatics that utilizations organic properties to recognize individuals. Since biometric frameworks recognizable proof an individual by the natural qualities, they are hard to counterfeit. Instances of biometrics are iris filter, different mark validation, voice acknowledgment framework and hand geometry framework. Presently the face acknowledgment this idea more worry for giving security to web banking this framework are utilized to picture preparing frameworks.

\section{RELATED WORK}

The utilization of human finger-vein attributes with the end goal of programmed client acknowledgment has increased a great deal of consideration in the ongoing years.

Revised Manuscript Received on May 15, 2020.

* Correspondence Author

MR.P.C.Karthik*, Computer Science and Engineering SRM Institute of Science and Technology Chennai ,India

M.Sai Deepthi, Computer Science and Engineering SRM Institute of Science and Technology Chennai, India

K.Abhiram, Computer Science and Engineering SRM Institute of Science and Technology Chennai ,India

(C) The Authors. Published by Blue Eyes Intelligence Engineering and Sciences Publication (BEIESP). This is an open access article under the CC BY-NC-ND license (http://creativecommons.org/licenses/by-nc-nd/4.0/)
Current best in class systems can give moderately great execution, yet they are emphatically needy upon the nature of the investigated finger-vein pictures. Right now, propose a convolutional-neural-organize based fingervein ID framework and examine the abilities of the planned system more than four openly accessible databases. The principle motivation behind this work is to propose a profound learning technique for finger-vein distinguishing proof, ready to accomplish stable and exceptionally precise execution when managing finger-vein pictures of various quality. Recognizing an individual is a difficult activity in our ordinary life. The traditional techniques incorporates the secret phrase, ID cards, and so on [1]. In any case, these characters can undoubtedly be abused, lost or shared. To beat the above impediments of the customary strategies, biometric framework has been presented. The biometric framework assumes a significant job in giving high-security applications, for example, outskirt control, movement and so on. This paper gives the itemized investigation of different modules, applications, techniques and difficulties of the multimodal biometric framework. As of late, as indicated by the rising improvement of savvy cell phones and tablet PC, portable web based business has significantly expanded because of the explanation that the capacity of keen cell phone and tablet PC are consolidated together. M-banking is consequently gotten increasingly helpful, powerful and opportune through the new portable correspondence frameworks. So as to raise the security of M-banking, a few banks receive the one-time secret key (OTP) to cure the conceivable M-banking taking danger. Previously, the OTP is sent to individual cell phone. However, right now a large portion of the savvy cell phone can performing M-banking effectively. In this manner, it increases higher danger of data security because of cell phone hacking. So as to give a solid and secure M-banking process without decline the accommodation simultaneously, in the paper one-time secret word (OTP) and individual biometric have been joined with individual distinguishing proof and secret key for confirmation while M-banking. As the customer side starts a solicitation for M-banking to the server side of a bank that gives M-banking administration, the server side will create an OTP with restricted period for enrollment the M-banking and transmit to the customer side. After receiving the OTP letter, the consumer side needs to verify whether the OTP letter is accepted and the perfect true server side needs provided it. After at that point, the customer side will enroll the on-line M-managing an account with the OTP in the predefined brief period. Subsequent to getting the administration demand, the server side will at that point demand the customer side to catch individual biometric, 


\section{Secure Connected Transactions using Face Verification}

for example, unique finger impression, iris, photograph, and so forth quickly for additional check with the existed information put away in the server side to forestall the $\mathrm{M}$ banking stealing. In the off probability that the single biometric has been identified as an old one, the server side would easily stop the M-banking. As the test is finally completed by the server side, at that point the customer side can easily exchange through M-banking. The current strategy can not be given exclusively. This work handles the issue of the insurance of secret private information. Uncommon consideration is given to web based banking. We made benefit arbitrary capacities to create erratic outcomes for gatecrashers. By making a rundown of passwords and by encoding each word in two distinct advances dependent on irregular capacities we get proficient twofold insurance. Extra security is offered by biometrical information, for example, fingerprints. The fingerprints are watermarked in a well-picked picture which serves a common key between the bank and its client. This picture is converged in the client's fingerprints by utilizing the numerical guideline of solitary worth disintegration (SVD). Subsequently we get an obscured picture that is just reasonable by the bank.

\section{SYSTEM DESIGN}

Fig-1.1

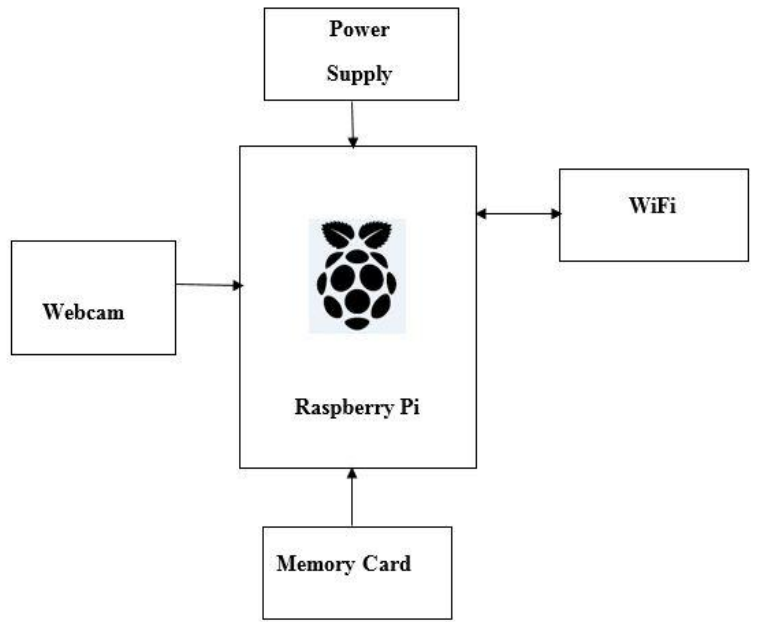

The face recognition is a positive biometric concept for uniquely identifiable evidence as far as its health and accommodation are concerned.

Internet of Things (IOT) and Computer Vision with the ATM card online exchange administration makes significantly more brilliant, progressed and easy to understand, as well.

Transaction from ATM card utilizing portable banking separated from utilizing an ATM is proposed in, so as to lessen the hour of exchange, yet there may be a security issue, if the framework is contrasted with any biometric security.

For substitute client Login should be possible utilizing OTP and furthermore the individual picture is caught and Mail to the Account Holder. Along these lines our framework is improve in Security contrasting with the current System.
BASIC ARCHITECTURE (GUI)

Fig-1.2

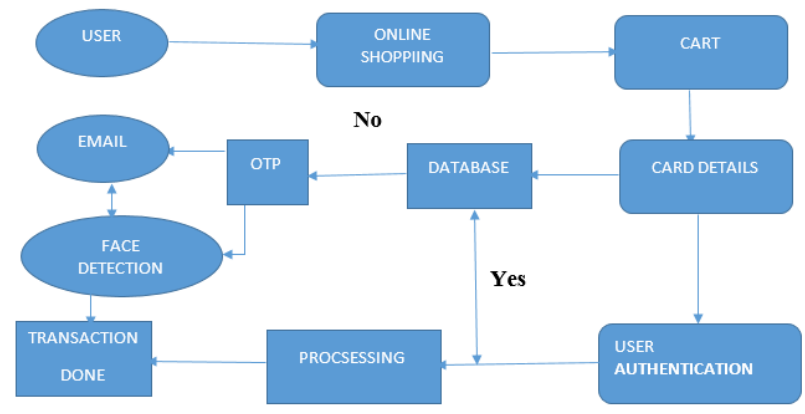

Block diagram of the workflow of face recognition

Fig-1.3

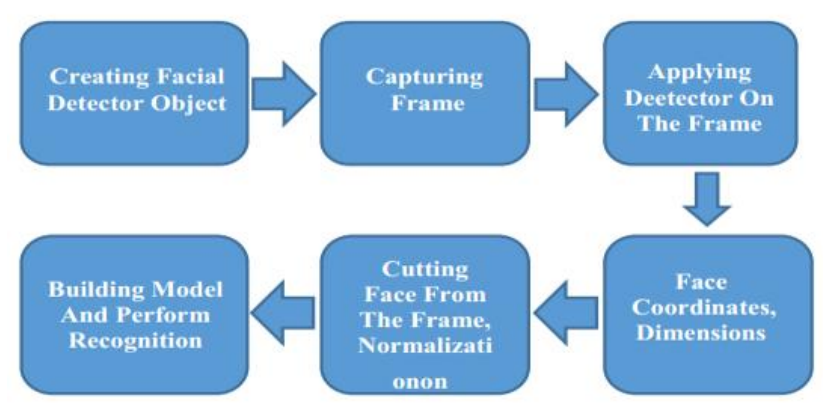

\section{CHALLENGES INVOLVED}

- Unauthorized individual may utilize the record.

- Transactions are done through console, so passwords may noticeable to other people.

- The hoodlums can additionally hack the Debit/MasterCard and have the option to do exchange from your record.

- However the downside in the current framework is that the client secret phrase might be miss use by others

- So just we structured a framework which causes us to utilize the Debit card with User Identification

\section{ALGORITHM}

\section{Key generation algorithm}

The way toward producing keys for cryptography. A private key and its relating open key; a key pair is utilized with a lopsided key (open key) calculation. A key is utilized to encode and decode whatever information is being scrambled/unscrambled.

Cryptographic systems of the modern day combine symmetric-key calculations and open key calculations. Symmetric-key equations use a single key alone; maintaining the secrecy of knowledge includes discreetness. Calculations for shared key use a shared key and a secret key. The free key is made available to everyone (regularly through computerized testament methods).

A transmitter scrambles information with the free key; this information may be unscrambled by only the private key holder.

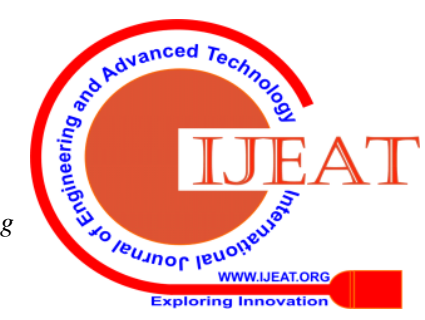




\section{OUTCOMES}

\section{EMAIL ALERT (Through Cloud)}

Face identification shows an unapproved individual subsequent to recognizing it sends exchange OTP to approve card holder. After exchange Person picture is sent to the approved individual email id.

\section{WEBCAM}

A webcam is a camcorder which encourages its pictures progressively to a PC or PC arrange, frequently by means of USB, Ethernet or Wi-Fi. Their most well known use is the foundation of video joins, allowing PCs to go about as videophones or video gathering stations. This basic use as a camcorder for the World Wide Web gave the webcam its name. This face acknowledgment framework more than security accommodate net financial idea or individual internet based life account. This task can give two kind of security technique first client can typical login then face acknowledgment for client this client and record client picture coordinate at that point start net financial procedure and online procedure

\section{RASPBERRY PI (Controller Unit- Image comparison} with data base)

Raspberry pi is a little Mastercard estimated PC equipped for performing different functionalities, for example, in observation frameworks, military applications, and so on. The different functionalities of the segments are given beneath. The different segments of Raspberry-Pi are

SD Card Slot is used to mount OS / boot / long haul data. The entire SD card capacity is around 8 GB.

Miniaturized scale USB Power Port gives $700 \mathrm{~mA}$ at 5A. RCA Video Out is associated with show if HDMI yield isn't utilized. It is principally used to convey sound and video signals. They are in any case called as A/V jacks.

Sound Out Digital sound is gotten if HDMI is utilized to acquire stereo sound. Here simple RCA association is utilized.

Ethernet Port is used for Internet communication. It even carries on a role of updating, simplifying modern programming. HDMI OUT (Multimedia High Resolution Interface) is used for HDTVs and HDMI-input displays. Similarly HDMI-HDMI is used here.

BROADCOM BCM 2835: In either case, it is defined as a chip device. It is a processor of $700 \mathrm{MHz}$. It has a Video Center IV GPU. GPIO allows us to monitor and cooperate with real world

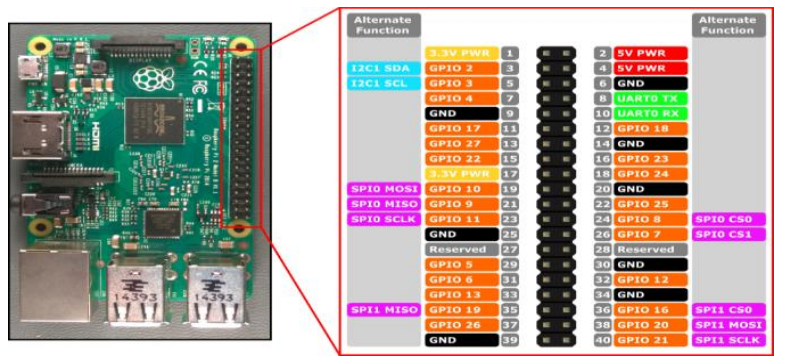

Fig-1.4
- $\quad$ SD Card

- Power Supply

- Cable

- Wifi

Software Requirements

- Language : Python

- Operating system : raspberry os

\section{CONCLUSION}

This task is created based on more need of security in Debit/Credit card Transaction framework. Presently a-day's online Transaction is getting less secure with developing approaches to hack/break PIN or secret key of Debit/Credit card. Thus we actualize client Identification utilizing Face Recognition to check the client. If there should be an occurrence of crisis circumstance the login should be possible utilizing OTP and furthermore the individual picture is caught and Mail to the Account Holder. Along these lines our framework is improve in Security contrasting with the current System.

\section{REFERENCES}

1. V. Cuervo, "Automated teller machine dispenser of debit cards," U.S Patent 6,105,009, August 2000

2. P. Viola and M. Jones, "Rapid Object Detection using a Boosted Cascade of Simple Features," Proc. IEEE Comp. Soc. Conf. USA, vol. 1, pp. 1-1, December 2001

3. G. Bradski and A. Kaehler, "Learning OpenCV: Computer vision with the OpenCV library," O'Reilly Med. Inc. USA, 2008

4. N. Bansal and N. Singla, "Cash withdrawl from ATM machine using Mobile banking," Int. Conf. Computational The. Inform. And Communication Tech. (ICCTICT) India, pp. 535-539, March 2016

5. J. Whitehill, G. Littlewort, I. Fasel, M. Bartlett and J. Movellan, "Toward Practical Smile Detection," IEEE Trans. Pattern Analysis and Intelligence IEEE Comp. Soc., vol. 31, pp. 2106-2111, November 2009

6. T. Ahonen, A. Hadid and M. Pietikainen, "Face Description with Local Binary Patterns: Application to Face Recognition," IEEE Trans. Pattern Analysis and Machine Intelligence IEEE Comp. Soc. vol. 28, pp. 2037-2041, December 2006

7. R. Khan, R. hasan, J. Xu, "SEPIA: Secure-PIN-Authentication-asaService for ATM Using Mobile and Wearable Devices," IEEE 3rd Int. Conf. Mobile Cloud Computing, Services, and Engg. , pp. 41-50, March 2015

8. M. S. Uddin, N. C. Das and A. Barua, "The mCard approach for Bangladesh: A smart phone based Credit/Debit/ATM card," 16th Int. Conf. Computer and Inform. Tech. Bangladesh, pp. 209-212, March 2014

9. S. Sridharan and K. Malladi, "New generation ATM terminal services," Int. Conf. Computer Communication and Inform. (ICCCI) India, pp. 1-6, January 2016

10. H. R. F. Najafabadi and M. R. F. Derakhshi, "Multipurpose smart SIM card based on mobile database and location dependent query," 6th Int. Conf. Application Inform. and Communication Tech. (AICT) Georgia, pp. 1-5, October 2012

11. Nelligani, B. M. Reddy, NV U. reddy and N. Awasti, "Smart ATM security system using FPR, GSM, GPS", Int. Conf. Inventive Computation Tech.(ICICT) India, vol. 3, pp. 1-5, August 2016

12. Christiawan, B. A. Sahar, A. F. Rahardian, and E. Muchtar, "Fingershield ATM - ATM Security System using Fingerprint Authentication," Int. Symposium Electronics and Smart Devices (ISESD) Indonesia, January 2019.

\section{Hardware Requirements}

- $\quad$ Raspberry Pi

- Camera

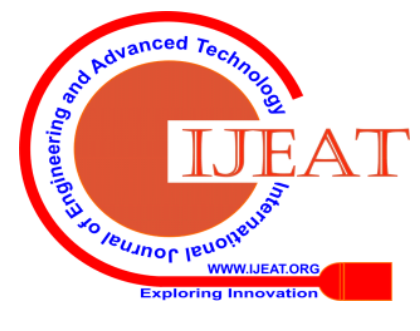

